\title{
Global surface temperature in relation to northeast monsoon rainfall over Tamil Nadu
}

\author{
S BALACHANDRAN*, R ASOKAN and S SRIDHARAN \\ Regional Meteorological Centre, 50(New 6) College Road, Chennai 600 006, India. \\ *e-mail: balaimd@yahoo.co.in
}

The local and teleconnective association between Northeast Monsoon Rainfall (NEMR) over Tamil Nadu and global Surface Temperature Anomalies (STA) is examined using the monthly gridded STA data for the period 1901-2004. Various geographical regions which have significant teleconnective signals associated with NEMR are identified. During excess (deficient) NEMR years, it is observed that the meridional gradient in surface air temperature anomalies between Europe and north Africa, in the month of September is directed from the subtropics (higher latitudes) to higher latitudes (subtropics). It is also observed that North Atlantic Oscillation (NAO) during September influences the surface air temperature distribution over north Africa and Europe. Also, the NAO index in January shows significant inverse relationship with NEMR since recent times. The central and eastern equatorial Pacific oceanic regions have significant and consistent positive correlation with NEMR while the western equatorial region has significant negative correlation with NEMR. A zonal temperature anomaly gradient index (ZTAGI) defined between eastern equatorial Pacific and western equatorial Pacific shows stable significant inverse relationship with NEMR.

\section{Introduction}

Tamil Nadu, located in southeast Peninsular India (figure 1), receives the major part of its annual rainfall during the northeast monsoon (NEM) season (the three-month period from October to December). While coastal Tamil Nadu receives about $60 \%$ of its annual rainfall, interior Tamil Nadu receives about $40-50 \%$ of annual rainfall during NEM season (IMD 1973). In comparison with Indian Summer Monsoon (ISM), the NEM is characterised by limited aerial extent and average lesser rainfall amount. During NEM season, Tamil Nadu generally receives rainfall due to the formation of trough of low, cyclonic circulation, easterly waves, low pressure area, depression and cyclonic storm over Bay of Bengal. Because the NE monsoon season is the major rainy season, the vicissitudes of the rainfall of Tamil Nadu state has led to considerable and widespread interest among the public/farmers and in government circles in recent years, in view of the frequent failure of northeast monsoon rainfall (NEMR) over Tamil Nadu and the consequent water scarcity condition. The study of interannual variability of NEMR is therefore essential in the understanding and prediction of the same.

Krishna Rao et al (1953) found that the NEMR is more variable in the coastal districts compared to interior districts. Ramaswamy (1972) in his study on the severe drought over Tamil Nadu during NEM period of 1968 showed that it is related to large scale anomalies in the upper level flow pattern in the middle and higher latitudes in the northern hemisphere. Sridharan and Muthuswamy (1990) showed that during most of the El-Nino years, NEMR over Tamil Nadu is normal or above normal. They also indicated the existence of negative correlation between seasonal western Atlantic hurricane activity and NEMR over Tamil Nadu. Raj et al (1993) and Raj (1998) have identified a few upper air parameters that have predictive

Keywords. Global surface temperature anomaly; northeast monsoon rainfall; teleconnection; north Atlantic oscillation. 


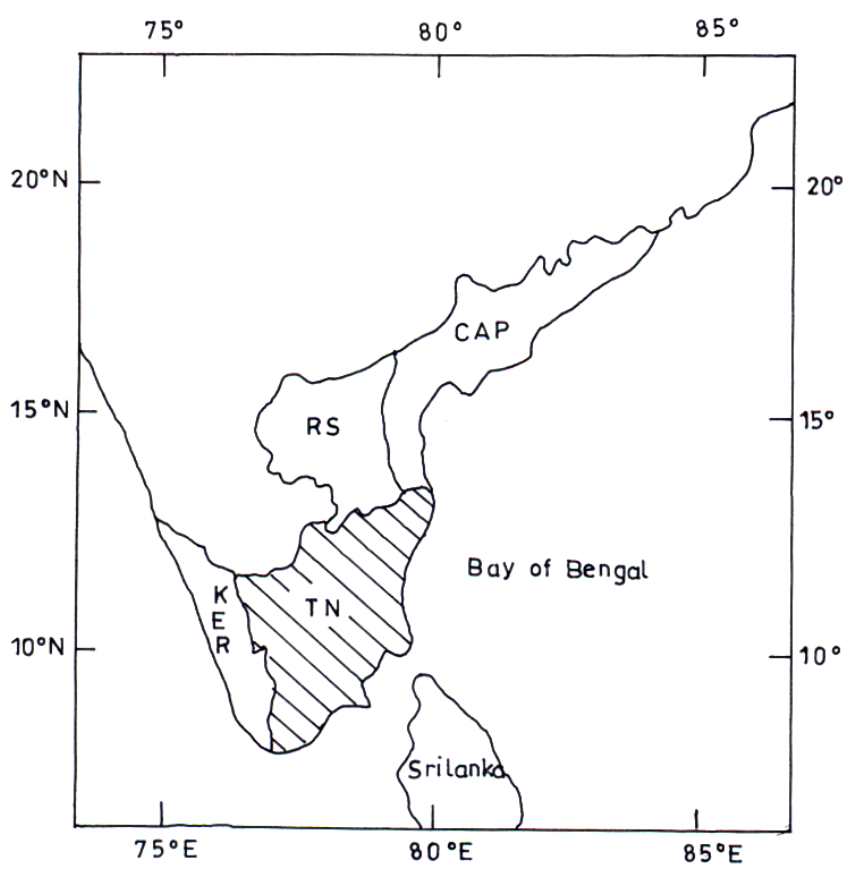

Figure 1. Geographical location of area of study (Tamil Nadu (TN)).

Table 1. List of excess and deficient northeast monsoon years over Tamil Nadu.

\begin{tabular}{cc}
\hline $\begin{array}{c}\text { Excess NEMR } \\
\text { years }\end{array}$ & $\begin{array}{c}\text { Deficient NEMR } \\
\text { years }\end{array}$ \\
\hline 1902 & 1904 \\
1913 & 1908 \\
1914 & 1909 \\
1919 & 1917 \\
1920 & 1924 \\
1922 & 1926 \\
1925 & 1928 \\
1930 & 1938 \\
1931 & 1947 \\
1932 & 1949 \\
1940 & 1950 \\
1944 & 1951 \\
1946 & 1952 \\
1966 & 1958 \\
1969 & 1961 \\
1972 & 1968 \\
1977 & 1974 \\
1978 & 1975 \\
1979 & 1980 \\
1993 & 1984 \\
1996 & 1986 \\
1997 & 1988 \\
& 1995 \\
& 2000 \\
& 2001 \\
\hline
\end{tabular}

potential for NEMR over Tamil Nadu and the southern region.

The interannual variability of ISM rainfall and NEMR is determined by external forcings and nonlinear internal dynamics. Surface air temperature is one of the factors that influence monsoon variability. The distribution of surface air temperature over land and sea determines the locations of heat source and sink which in turn affect circulation patterns through thermal and latent heat energy exchange between atmosphere and the surface beneath. A number of studies addressed the relationship between ISM, and land and sea surface temperatures (e.g., Sikka (1980); Verma et al (1985)). Rajeevan et al (1998) examined the global land surface air temperature anomaly patterns in association with interannual variability of ISMR. During the last few decades there has been a large number of observation and global circulation model (GCM) sensitive studies relating sea surface temperature (SST) over Indian and Pacific Oceans with ISMR. However, similar attempts related to NEM were limited. Recently Pai $(2003,2004)$ discussed the prominent teleconnection patterns in the monthly global gridded surface air temperature anomalies associated with the interannual variability of ISMR. In a similar manner, the association between the global surface air temperature anomalies and NEMR is examined in the present study.

\section{Data}

The main data set used is the grid point monthly global temperature anomalies for the period 1901-2004. This data set is a combination of land surface air temperature anomalies and SST anomalies on a $5^{\circ} \times 5^{\circ}$, latitude $\times$ longitude, grid box (Jones et al 1997). The base period for both land and SST anomalies is from 1961 to 1990 . The SST anomalies were constructed from the updated version of Meteorological Office Historical Sea Surface Temperature (MOHSST 6). The land surface air temperature and the SST anomalies were combined using the algorithm developed by Parker et al (1994). Nicholls et al (1996) showed that there is a trend in global surface temperature that is most prominent during recent decades. Hence the monthly grid point surface temperature anomalies for the period 1901-2004 were detrended by means of simple linear regression method and these detrended anomalies are used in further analysis.

The NEMR series of Tamil Nadu during 1901-2004 was prepared as follows: The daily rainfall data of 173 stations in Tamil Nadu for the period 1901-1996 was obtained from National Data Center, Pune. Using this daily data, the seasonal rainfall series of Tamil Nadu subdivision for the period 1901-1996 was constructed. The data for the remaining part of the series was collected from 
the weekly weather report of Area Cyclone Warning Centre, Chennai (Tamil Nadu). As per IMD criteria, excess (deficient) monsoon years for subdivision is defined as whenever the percentage departure of seasonal rainfall from normal of subdivision is more (less) than $+19 \%(-19 \%)$. Using this criteria, the excess and deficient NE monsoon years during the period 1901-2004 were identified. During this period there are 22 excess NE monsoon years and 25 deficient NE monsoon years and these are listed in table 1. Another data set used for the present study is the North Atlantic Oscillation

\section{$\mathrm{N}$}

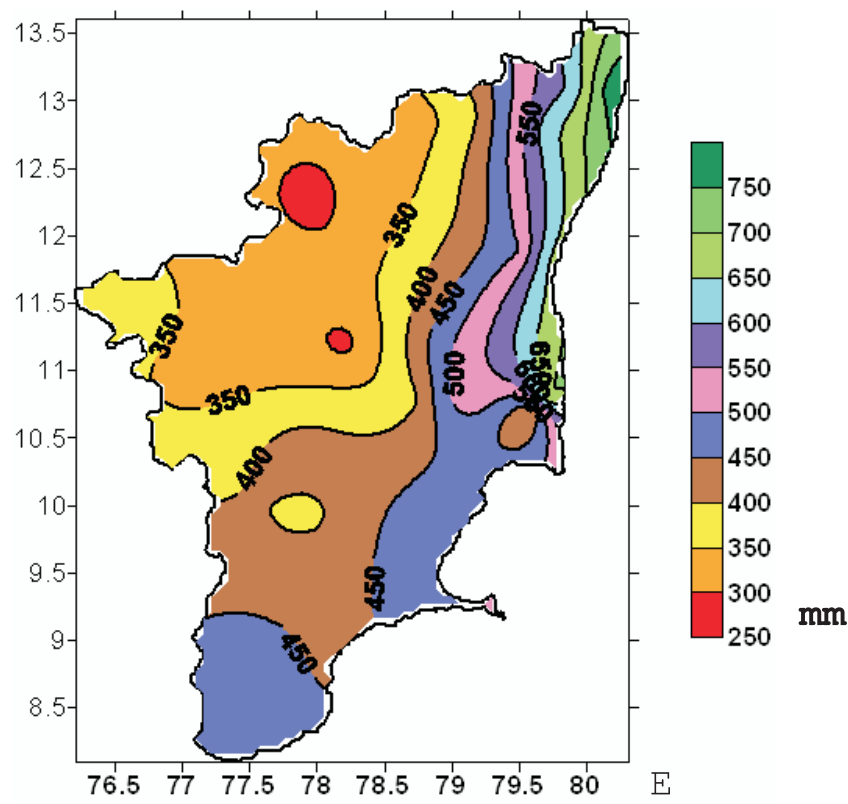

Figure 2(a). Mean rainfall for northeast monsoon season during the period 1901-2004 over Tamil Nadu. The horizontal dotted lines indicate the limits $(+/-19 \%)$ of the normal NEMR.
(NAO) index. NAO is one of the large scale oscillations in the atmosphere that has teleconnective influence potential (Van Loon and Rodgers 1978; Dugam et al 1997). The NAO index is defined as the pressure difference between Azores high (AH) and Icelandic Low (IL). A high (low) NAO index implies strong (weak) westerly winds between $\mathrm{AH}$ and IL. The NAO index for the period 1901-2004 was downloaded from www.cru.uea.ac.uk.

\section{Results and discussions}

\subsection{Interannual variation of NEMR}

Tamil Nadu receives mean rainfall of about $450 \mathrm{~mm}$ with coefficient of variation $28 \%$ during NEMR season. Figure 2(a) shows the mean rainfall distribution over Tamil Nadu during NEMR season. During the entire NEM season, northeast coastal Tamil Nadu receives rainfall exceeding $600 \mathrm{~mm}$. Generally rainfall decreases westwards from coastal area to inland and from north to south. Figure 2(b) shows the NEMR of Tamil Nadu during the period 1901-2004 expressed as percentage departure from long term normal. Out of 104 years of present study, NEMR over Tamil Nadu was below normal for 54 years (i.e., about 53\%). The NEMR over Tamil Nadu was continuously below (above) long term average for a maximum of 9(4) years. Ropelewski and Halpert (1987) found that NEMR over south Tamil Nadu is enhanced (diminished) during the well-known El-Niño episodes that refer to the events of warming (cooling) over central and equatorial Pacific Ocean. Out of 24 years of El-Niño during the period of study, NEMR was normal or excess during 23 years (except during the year 1951).

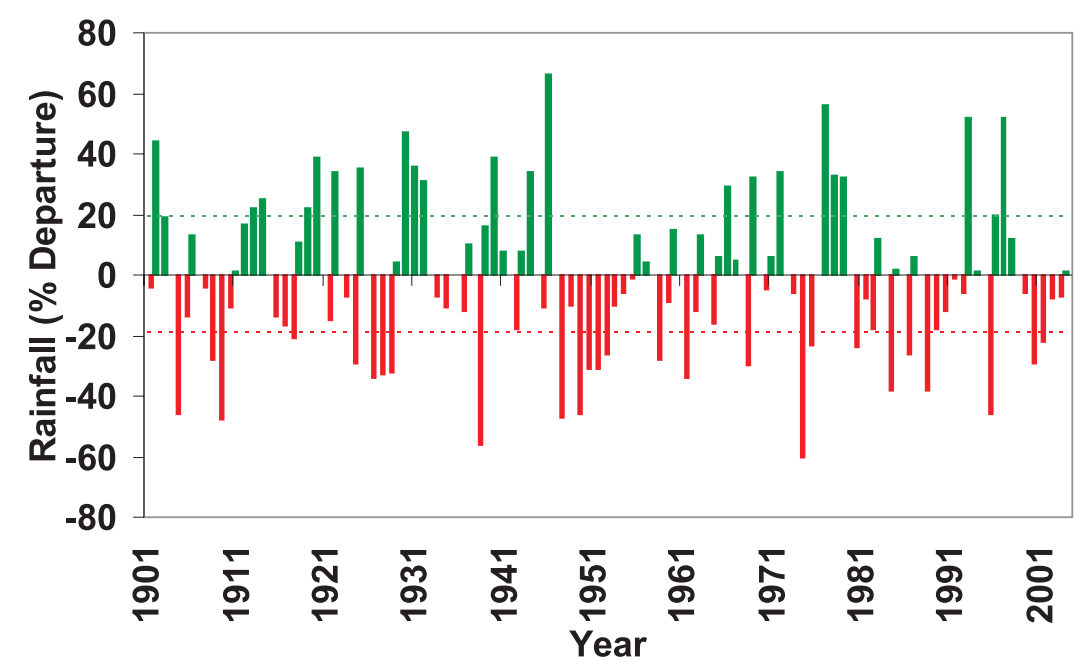

Figure 2(b). NEMR of Tamil Nadu for the period 1901-2004 expressed as percentage departure from long term normal. 


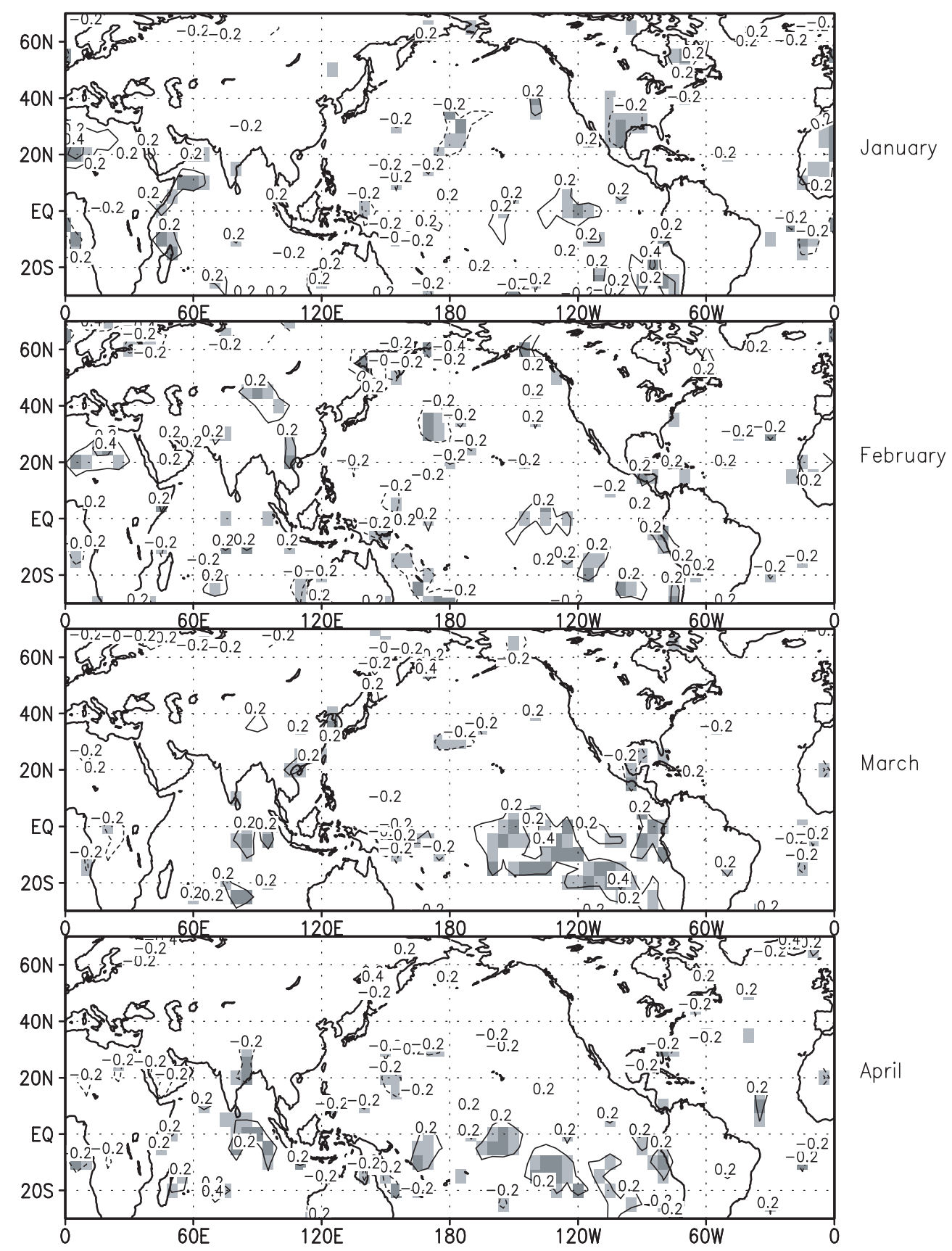

Figure 3(a). Correlation Coefficients (CC) between NEMR and STA anomalies during the months of January to April for the period 1901-2004. Contour interval is 0.2. Grid boxes with CC significant at $1 \%$ (5\%) are shaded dark (light).

\subsection{Patterns of correlation between surface air temperature anomalies and NEMR}

The local as well as global teleconnections between surface temperature anomalies and NEMR are studied by means of correlation between STA and NEMR. The Correlation Coefficient (CC) patterns for the twelve months from January to December are shown in figure 3. In this figure, the grid boxes with CCs significant at 1\% (5\%) are shaded dark (light). In the $\mathrm{CC}$ patterns, the positive $\mathrm{CC}$ regions indicate that when the surface air temperatures over these areas are warmer (cooler) than normal, the NEMR is above (below) normal. Similarly, the negative CC regions indicate that the surface air temperatures over these areas are cooler (warmer) than normal when the NEMR is above (below) normal.

The main feature that could be noticed from figure 3 is the significant positive CC over equatorial Pacific region that remained consistent during all months from March to December. In the month of January, significant positive CCs are noticed over Arabian Sea, Mozambique channel, north Africa, 


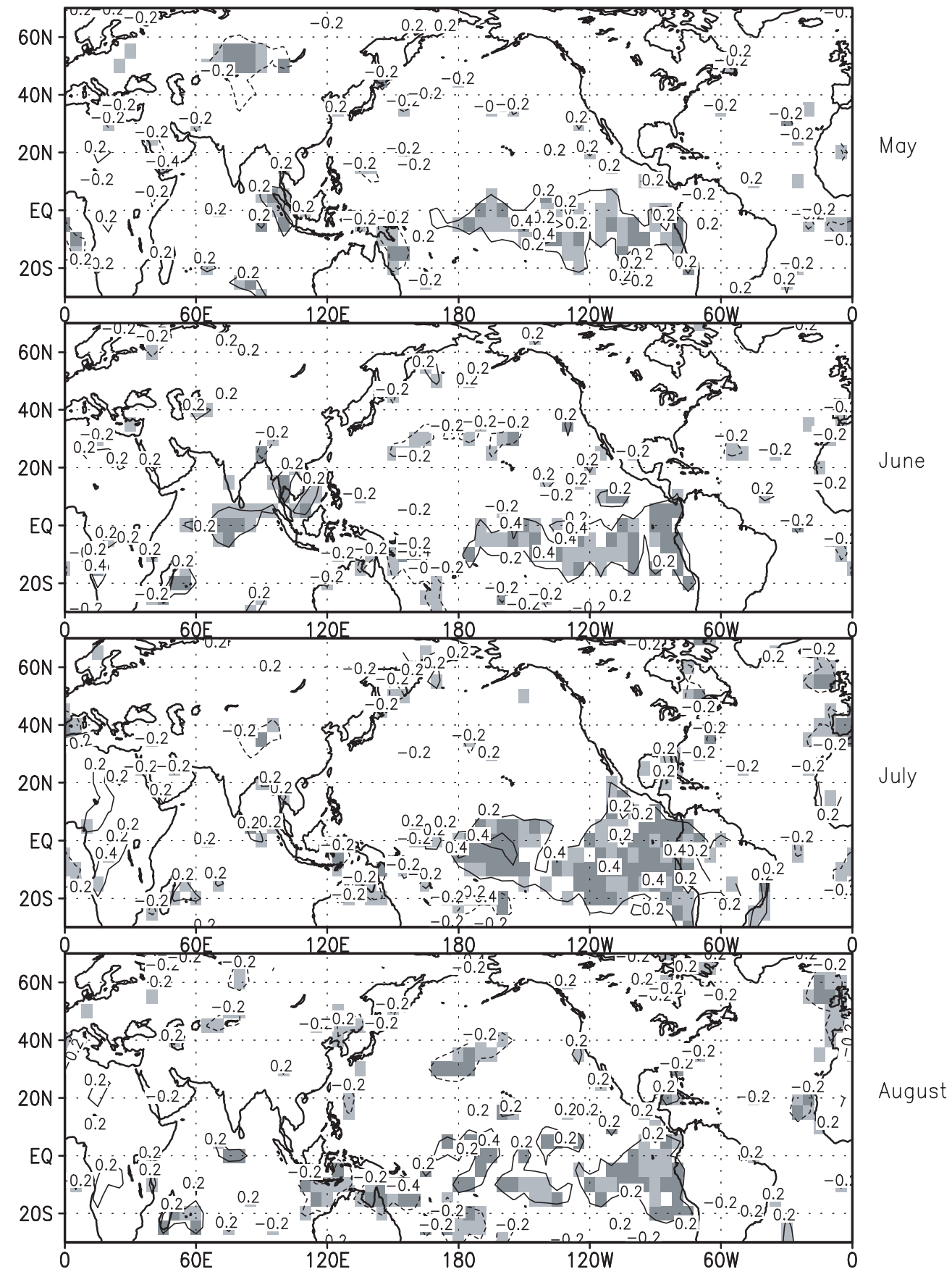

Figure 3(b). Correlation Coefficients (CC) between NEMR and STA anomalies during the months of May to August for the period 1901-2004. Contour interval is 0.2. Grid boxes with CC significant at $1 \%$ (5\%) are shaded dark (light).

east coast of north America, eastern equatorial Pacific region. Significant negative CCs are noticed over Mexican region of north America. During February, significant positive CCs are noticed over central China region, Sudan and west Africa region. Significant negative CCs are noticed over Coral Sea region off the coast of Australia. During March significant positive CCs are noticed over eastern equatorial Indian Ocean region while negative CCs are seen over higher latitudes of northern hemisphere. In the month of April, northwest
Pacific region and northeast India indicate negative relationship with NEMR while equatorial Indian Ocean indicates significant positive correlation with NEMR. During May, north China region, NW Pacific and northeast Japan regions indicate negative correlation with NEMR. In the month of June, significant positive CCs are noticed over equatorial Indian Ocean and Thailand while negative CCs are noticed over subtropical Pacific region. From June onwards, the Pacific Ocean north of Australia has an inverse relation with 


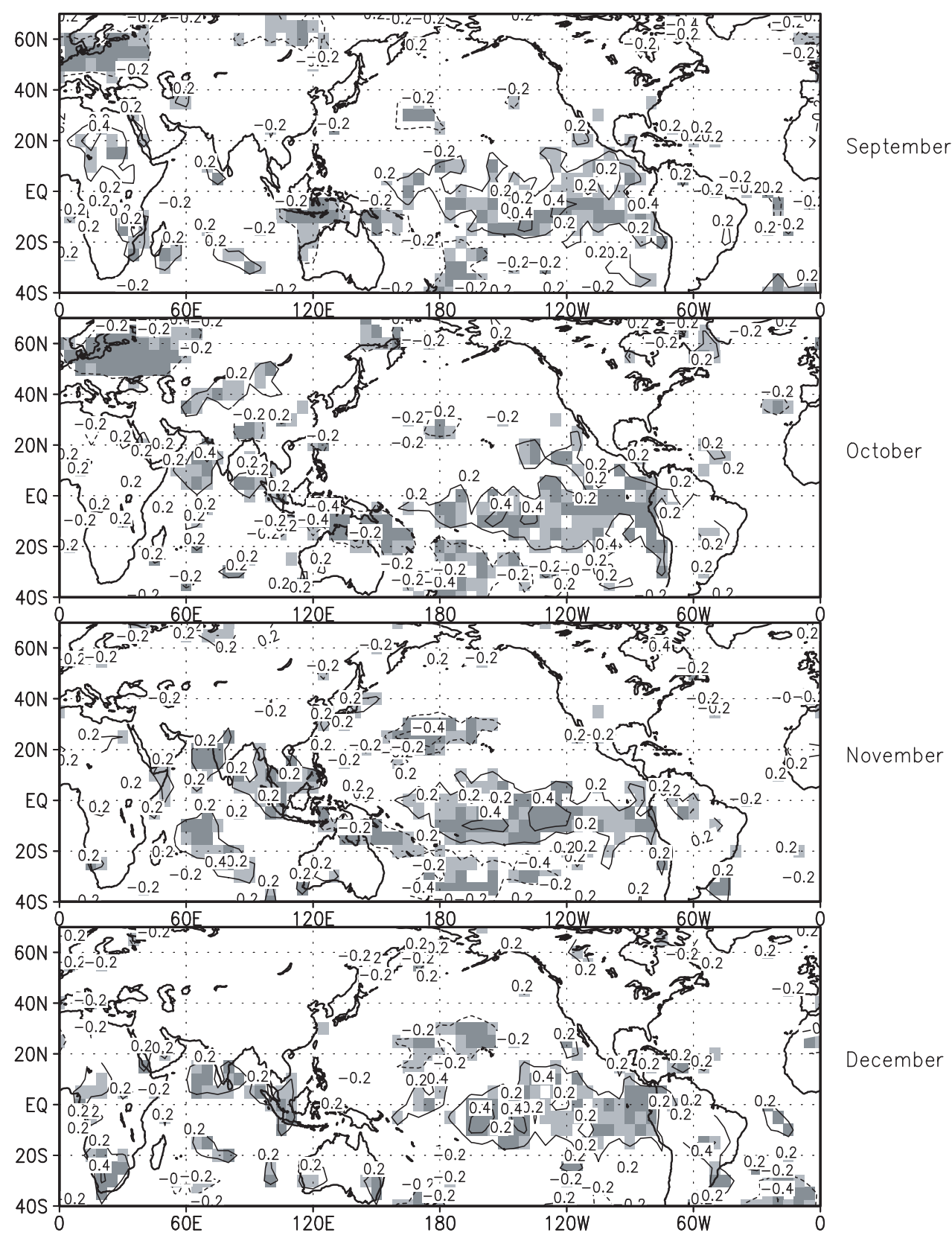

Figure 3(c). Correlation Coefficients (CC) between NEMR and STA anomalies during the months of September to December for the period 1901-2004. Contour interval is 0.2. Grid boxes with CC significant at 1\% (5\%) are shaded dark (light).

NEMR and this continues up to November. In September, the tropical African region (Europe) has a significant direct (inverse) relation with NEMR. Most of the features of CC pattern that are noticed in the month of September continues during October to December. Also north Indian Ocean areas show significant positive correlation with NEMR from October to December.

\subsection{Teleconnective signal regions}

Based on the spatial pattern of CC between NEMR and surface temperature anomalies (figure 3 ), some of the geographical regions that have the potential for predicting NEMR are noticed and these are listed in table 2. The CC between area averaged temperature anomalies (AATA) over each of the region and NEMR for various sliding 30 years periods are also given in the same table. The 30year moving CCs between AATA and NEMR over each of the regions are shown in the figure 4 . The values in table 2 and figure 4 indicate that the CCs between AATA over the selected regions and NEMR are significant and generally show good stability except during small periods.

Figure 5 shows the scatter diagram between NEMR and AATA over regions listed in table 2. As shown in this figure, most of the deficient NEMR 
Table 2. Correlation co-efficient between temperature anomalies averaged over different geographical regions and NEMR over Tamil Nadu for various periods. Significant levels for CC above and equal to 5\% are given in brackets.

\begin{tabular}{|c|c|c|c|c|c|c|c|c|}
\hline \multirow[b]{2}{*}{ Sl. no } & \multirow[b]{2}{*}{ Region } & \multirow[b]{2}{*}{ Spatial domain } & \multirow[b]{2}{*}{ Month } & \multicolumn{5}{|c|}{ CC with NEMR for various time period } \\
\hline & & & & 1901-2004 & $1901-30$ & $1931-60$ & $1961-90$ & $1975-2004$ \\
\hline 1 & $\begin{array}{l}\text { Equatorial } \\
\text { Indian } \\
\text { Ocean }\end{array}$ & $\begin{array}{l}80^{\circ} \mathrm{E}-100^{\circ} \mathrm{E} / \\
5^{\circ} \mathrm{S}-5^{\circ} \mathrm{N}\end{array}$ & April & $\begin{array}{l}0.27 \\
(1 \%)\end{array}$ & 0.01 & $\begin{array}{l}0.39 \\
(5 \%)\end{array}$ & $\begin{array}{l}0.45 \\
(1 \%)\end{array}$ & $\begin{array}{l}0.37 \\
(5 \%)\end{array}$ \\
\hline 2 & $\begin{array}{l}\text { Eastern } \\
\text { equatorial } \\
\text { Pacific }\end{array}$ & $\begin{array}{l}70^{\circ} \mathrm{W}-120^{\circ} \mathrm{W} / \\
15^{\circ} \mathrm{S}-15^{\circ} \mathrm{N}\end{array}$ & July & $\begin{array}{l}0.41 \\
(5 \%)\end{array}$ & $\begin{array}{l}0.35 \\
(5 \%)\end{array}$ & 0.32 & $\begin{array}{l}0.46 \\
(1 \%)\end{array}$ & $\begin{array}{l}0.40 \\
(5 \%)\end{array}$ \\
\hline 3 & $\begin{array}{l}\text { Central } \\
\text { equatorial } \\
\text { Pacific }\end{array}$ & $\begin{array}{l}140^{\circ} \mathrm{W}-170^{\circ} \mathrm{W} / \\
10^{\circ} \mathrm{S}-10^{\circ} \mathrm{N}\end{array}$ & July & $\begin{array}{l}0.47 \\
(1 \%)\end{array}$ & $\begin{array}{l}0.54 \\
(1 \%)\end{array}$ & $\begin{array}{l}0.42 \\
(5 \%)\end{array}$ & $\begin{array}{l}0.51 \\
(1 \%)\end{array}$ & $\begin{array}{l}0.37 \\
(5 \%)\end{array}$ \\
\hline 4 & $\begin{array}{l}\text { Western } \\
\text { Europe }\end{array}$ & $\begin{array}{l}0-40^{\circ} \mathrm{E} / \\
45^{\circ} \mathrm{N}-60^{\circ} \mathrm{N}\end{array}$ & Sept. & -0.32 & -0.30 & -0.29 & $\begin{array}{l}-0.38 \\
(5 \%)\end{array}$ & $\begin{array}{l}-0.38 \\
(5 \%)\end{array}$ \\
\hline 5 & Indonesia & $\begin{array}{l}110^{\circ} \mathrm{E}-130^{\circ} \mathrm{E} / \\
10^{\circ} \mathrm{S} \text {-equator }\end{array}$ & Sept. & $\begin{array}{l}-0.40 \\
(5 \%)\end{array}$ & $\begin{array}{l}-0.49 \\
(1 \%)\end{array}$ & $\begin{array}{l}-0.37 \\
(5 \%)\end{array}$ & $\begin{array}{l}-0.41 \\
(5 \%)\end{array}$ & $\begin{array}{l}-0.35 \\
(5 \%)\end{array}$ \\
\hline 6 & $\begin{array}{l}\text { Southeast } \\
\text { Pacific }\end{array}$ & $\begin{array}{l}110^{\circ} \mathrm{W}-130^{\circ} \mathrm{W} / \\
10^{\circ} \mathrm{S} \text {-equator }\end{array}$ & Sept. & $\begin{array}{l}0.40 \\
(5 \%)\end{array}$ & 0.25 & 0.30 & 0.32 & $\begin{array}{l}0.45 \\
(1 \%)\end{array}$ \\
\hline
\end{tabular}

years are in the lower left quadrant and most of the excess NEM years are in the upper right quadrant of the scatter diagram for the regions of eastern equatorial Pacific (during July), central equatorial Pacific (during July) and southeast Pacific (during September). On the other hand, most of the deficient NEMR years are in the lower right quadrant and most of the excess NEM years are in the upper left quadrant of the scatter diagram over regions of western Europe. Thus the AATA over selected regions show potential to predict NEMR.

\subsection{Composites of surface air temperature anomalies during excess and deficient NEMR years}

As seen in figure 3 , it is observed that during the month of September, the CCs over regions of northern Africa around $15^{\circ} \mathrm{N}$ to $20^{\circ} \mathrm{N}$ latitude are positive while CCs over Eurasian region around $50^{\circ} \mathrm{N}$ to $60^{\circ} \mathrm{N}$ latitude are negative. This means that above (below) normal NEMR years are associated with increased (decreased) south-north temperature gradient in the month of September from subtropics (high latitudes) to higher latitudes (subtropics) over the longitudinal belt $\left(0-40^{\circ} \mathrm{E}\right)$. Also significant positive CCs are observed over the central and eastern equatorial Pacific and significant negative CCs are observed over the western Pacific region. These aspects are examined further here. Figure 6 ( $\mathrm{a}$ and $\mathrm{b}$ ) shows the composite surface temperature anomalies for deficient NEMR years and differences in the composite surface temperature anomalies between deficient and excess years during the month of September. The student's t-test (WMO 1966) is used to test the statistical significance of the differences in the composite patterns. In figure 6(a), the regions of positive STA are shaded and in figure $6(\mathrm{~b})$, the grid boxes with CCs significant at 1\% (5\%) are shaded dark (light). It is seen from figure 6(a) that during deficient NEMR years, the surface temperatures over western Europe and the Siberian region are warmer than normal while that over north Africa and its neighbourhood are colder than normal. This indicates that the meridional temperature gradient in the surface air temperature anomalies between north Africa and Europe is directed from higher latitudes to lower latitudes. On the other hand, as seen from figure $6(\mathrm{~b})$, this meridional temperature gradient in STA gets reversed and is directed from lower latitudes to higher latitudes.

Pai (2004) discussed the relationship between surface air temperature anomaly gradients and Indian summer monsoon rainfall (ISMR) and showed that the winter season meridional temperature anomaly gradient over Europe is directed towards equator (pole) during excess (deficient) ISMR. The present study indicates that the September month meridional temperature anomaly gradient over Europe is directed towards pole (equator) during excess (deficient) NEMR (figure 2(a) of Pai (2004) vs figure 6 of present study). Thus the surface air temperature anomaly distribution over north Africa and Europe influence both ISMR as well as NEMR in a dissimilar way at different time lags.

Rajeevan et al (1998) showed that NAO is one of the factors that influence the temperature distribution over Europe in the month of January. 

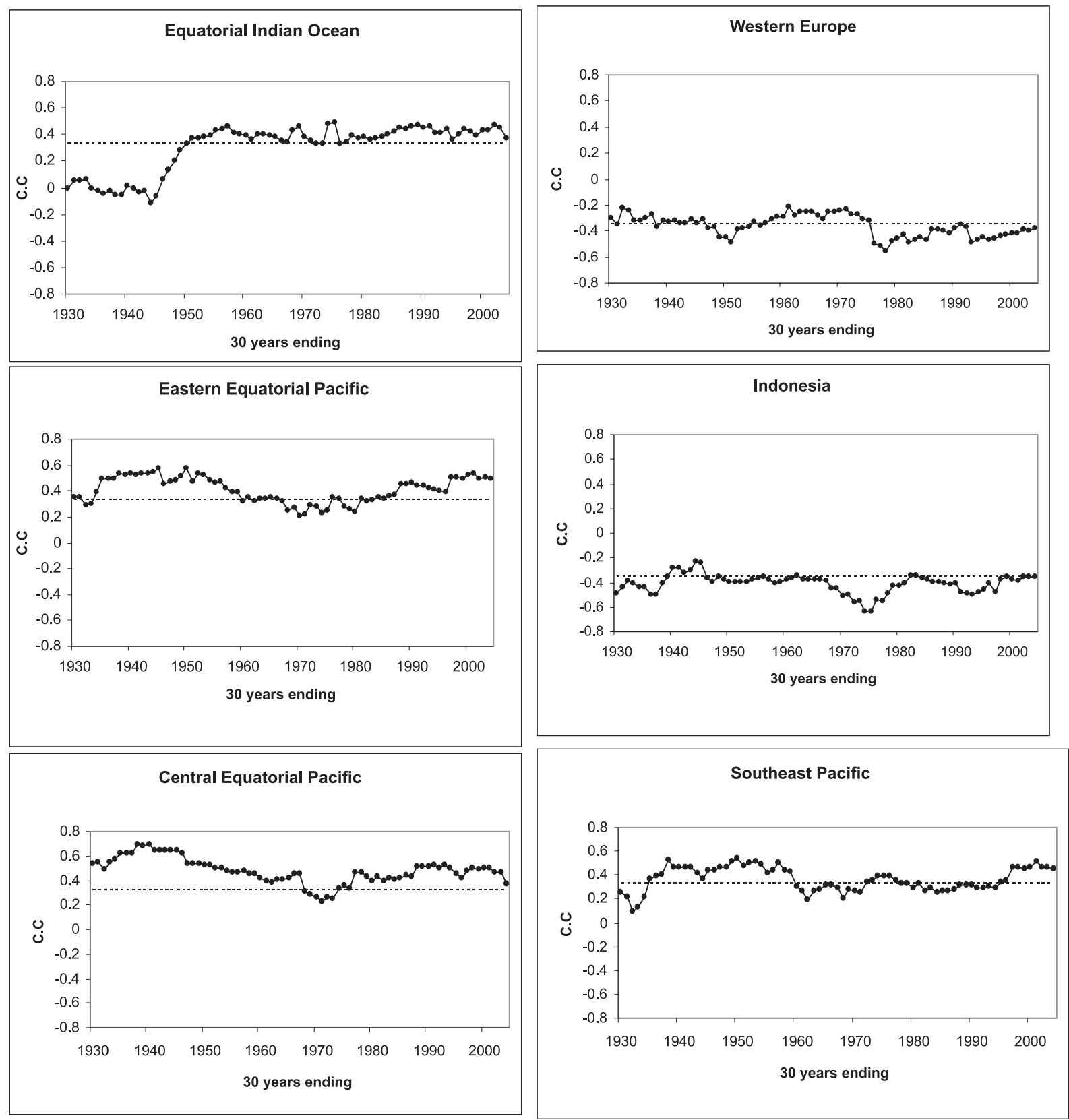

Figure 4. 30 years moving CCs between NEMR and area averaged surface temperature anomalies averaged over six geographical regions. The horizontal dotted line corresponds to CC significant at $5 \%$.

Similarly, in order to examine the influence of NAO over surface air temperature over Europe in the month of September, the spatial pattern of CC between NAO index (September) and the surface air temperature anomalies during September was prepared and is shown in figure 7 . This plot was made using data from the web page of NOAA - CIRES climate diagnostic center, Boulder, Colorado (www.cdc.noaa.gov). From this figure, it is noted that during the high NAO index phase, the temperature anomalies over Europe, south China Sea and adjoining sea of Japan are positive. On the other hand, temperature anomalies over western
Asia, north Indian Ocean, northeast Russia and equatorial Pacific region are negative. These temperature anomalies get reversed during low index phase of NAO. Hence, the warm (cold) temperature anomalies over Europe and Siberian region in the month of September during below (above) normal NEMR years [figure 6(a) and 6(b)] seem to be related to NAO index.

The strong (weak) westerlies associated with high (low) NAO index phase advect more (less) warm oceanic air over the land mass of Europe resulting in the warm (cold) surface air temperature anomaly. During the withdrawal phase 

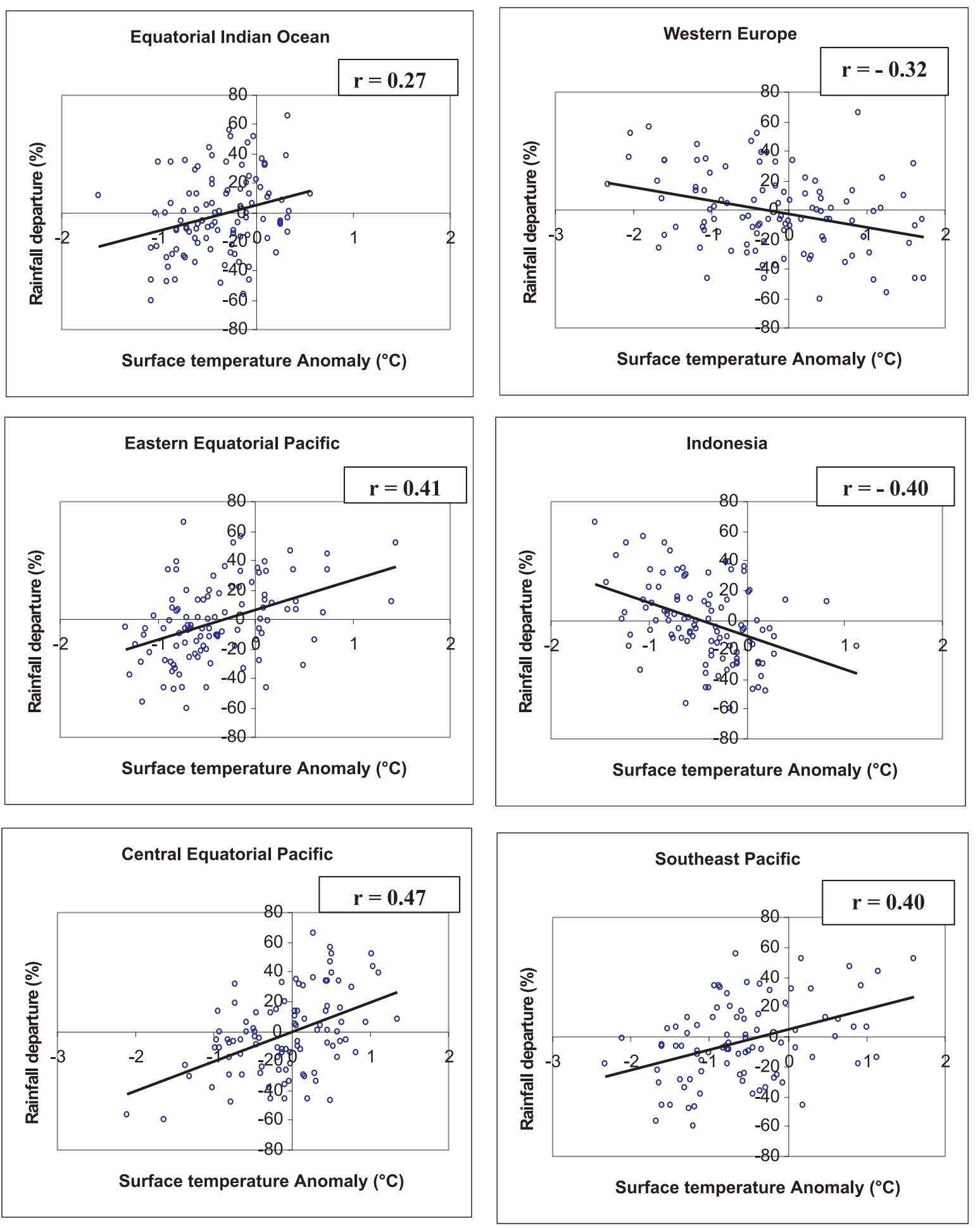

Figure 5. Scatter diagram between NEMR and area averaged surface temperature anomalies over six geographical regions. The CC between NEMR and area averaged surface temperature anomalies during the period 1901-2004 over each of six geographical regions are shown in the top right corner in the respective figures.

of Indian summer monsoon, before the onset of northeast monsoon, cold westerlies start to extend towards lower latitudes. Moreover, spells of heavy rain occur during NEMR season in association with strong surges of cold air that emanate from a large anticyclone located over Siberia and adjoining parts of China. The warm temperature anomalies observed in the present study over western Europe and Siberia during deficient NEMR years indicate the weak penetration of cold air from north and hence the evolution of weaker than normal poleward directed temperature gradient from low 
(a) (DEFICIENT)

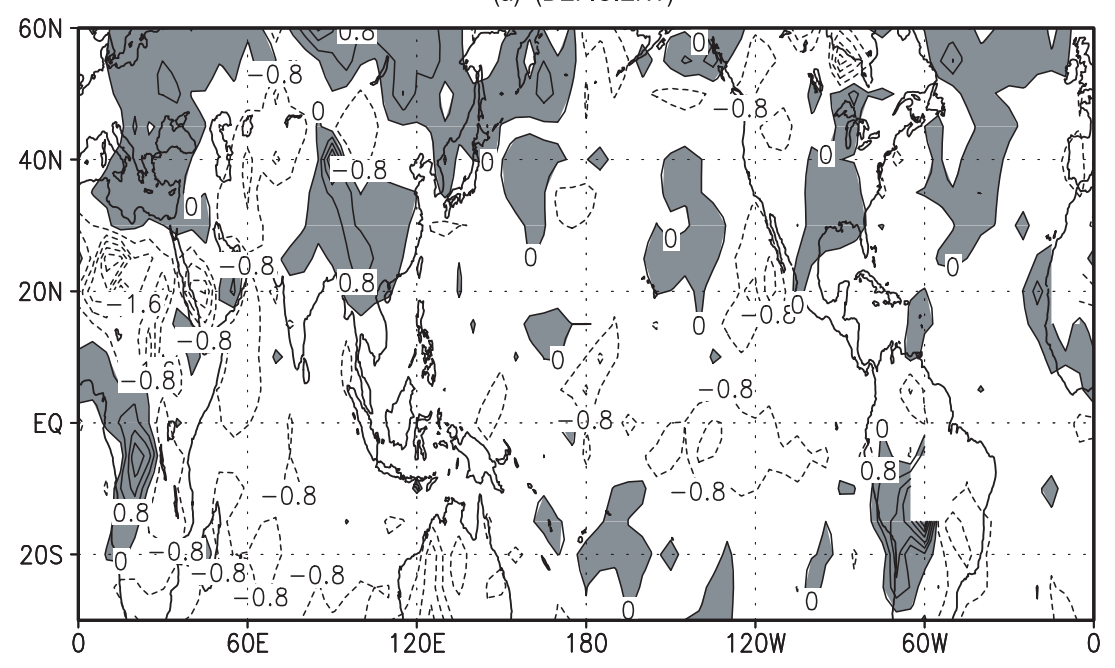

(b) (EXCESS - DEFICIENT)

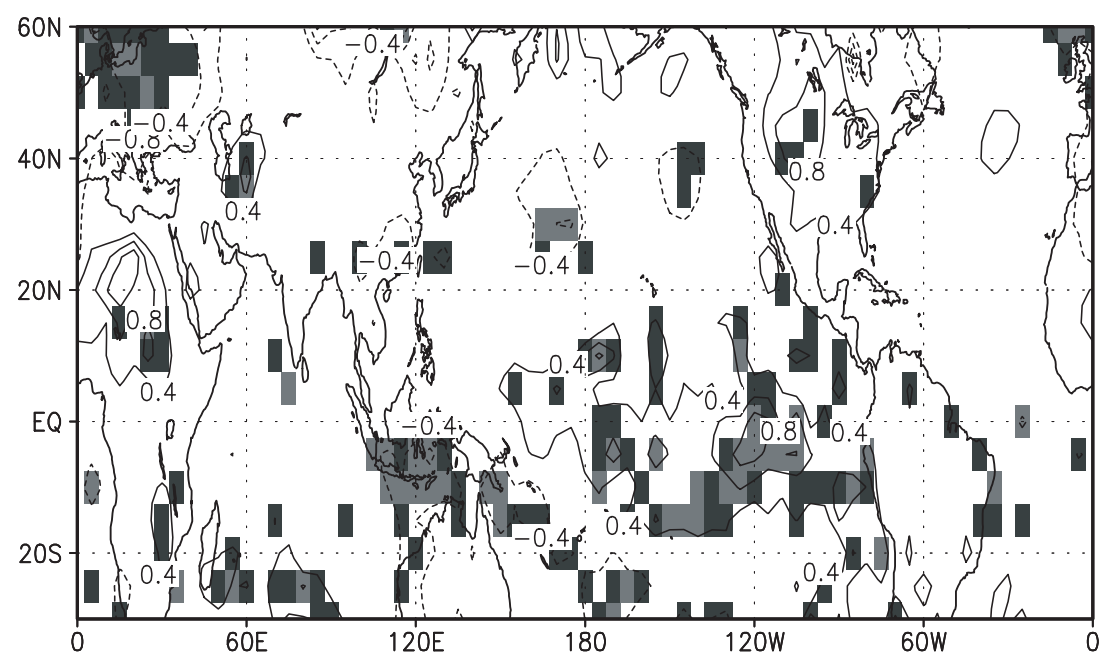

Figure 6. Composite surface air temperature anomalies during September for (a) deficient and (b) difference between excess and deficient (i.e., excess - deficient) northeast monsoon years. In (a) the contour interval is $0.4^{\circ} \mathrm{C}$ and the positive values are shaded. In (b) the grid boxes with anomaly differences significant at $1 \%(5 \%)$ are shaded dark (light).

to higher latitudes. Moreover, such warm temperature anomalies over the Siberian region during deficient NEMR years will diminish the climatological development of anticyclone over the Siberian region.

\subsection{Relationships among NAO, MTAGI and NEMR}

In order to use the temperature anomaly gradient between north Africa and Europe as a predictive signal for the performance of NEMR, a meridional temperature anomaly gradient index (MTAGI) is defined as the difference between area averaged temperature anomalies in the latitudinal belts $50^{\circ} \mathrm{N}-60^{\circ} \mathrm{N}$ and $15^{\circ} \mathrm{N}-20^{\circ} \mathrm{N}$ over the longitudinal range $\left(20^{\circ} \mathrm{E}-25^{\circ} \mathrm{E}\right)$. The $\mathrm{CC}$ between NEMR and September month MTAGI for the period $1901-2004$ is -0.36 (significant at $1 \%$ ). The 30 years moving correlation between NEMR and September month MTAGI is shown in figure 8(a). During recent times, the value of this CC is -0.35 (significant at $5 \%$ ) for the 30 years ending in 2004 .

It is seen earlier that the temperature anomaly distribution over Europe and north African region during the month of September could be influenced by NAO. The CC between September NAO index and MTAGI during the period 1901-2004 is 0.24 (significant at 10\%). In fact, the NAO index during winter season (December to February) shows significant CC of -0.16 (significant at $10 \%$ ) for the period 1901-2004 with NEMR. The 30 years sliding 


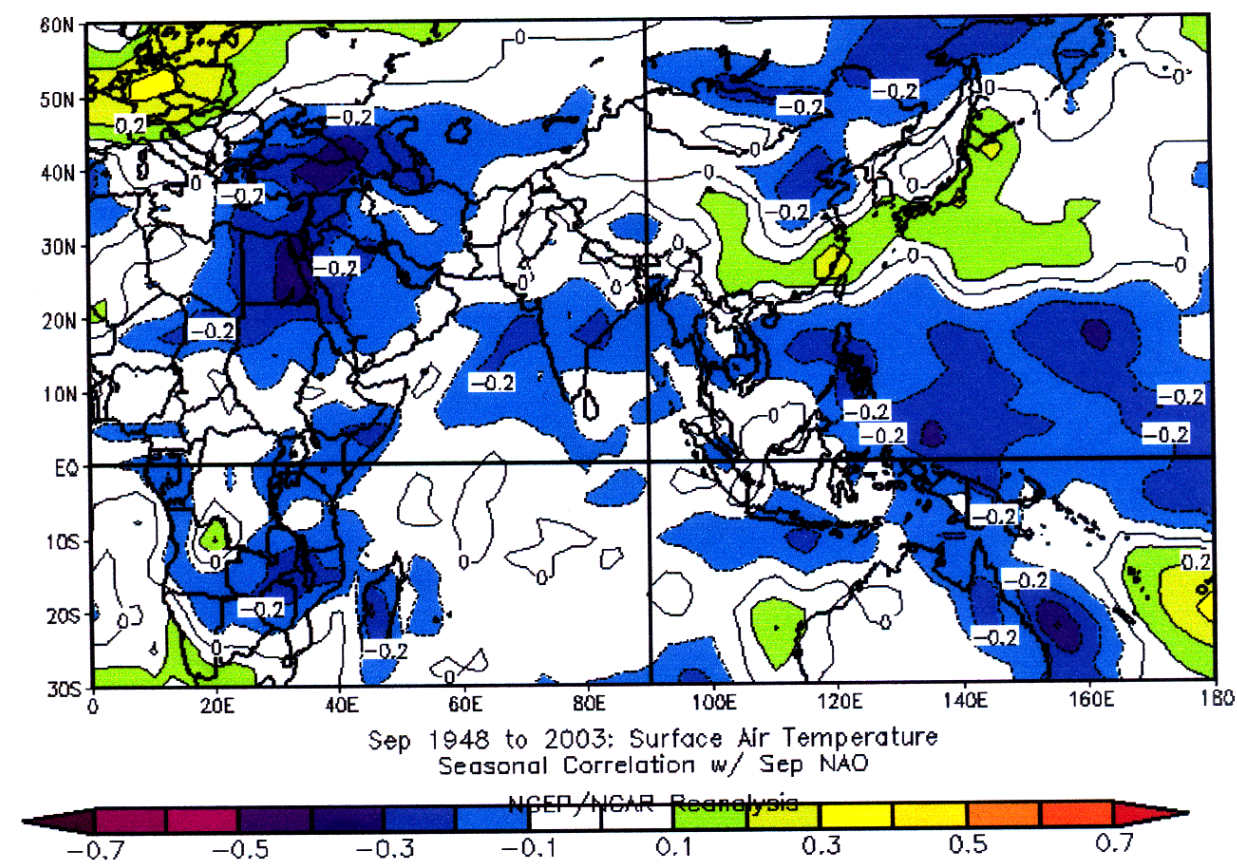

Figure 7. Correlation coefficients between NAO index and surface air temperature anomalies during September month.

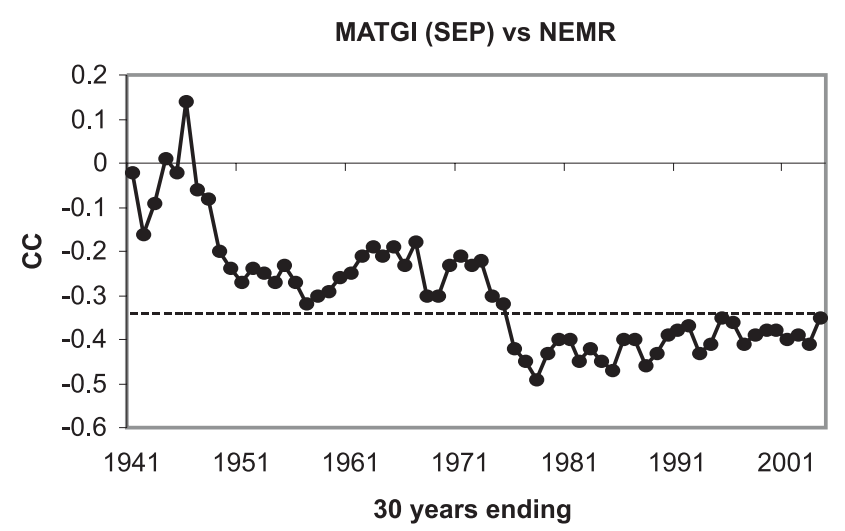

(a)

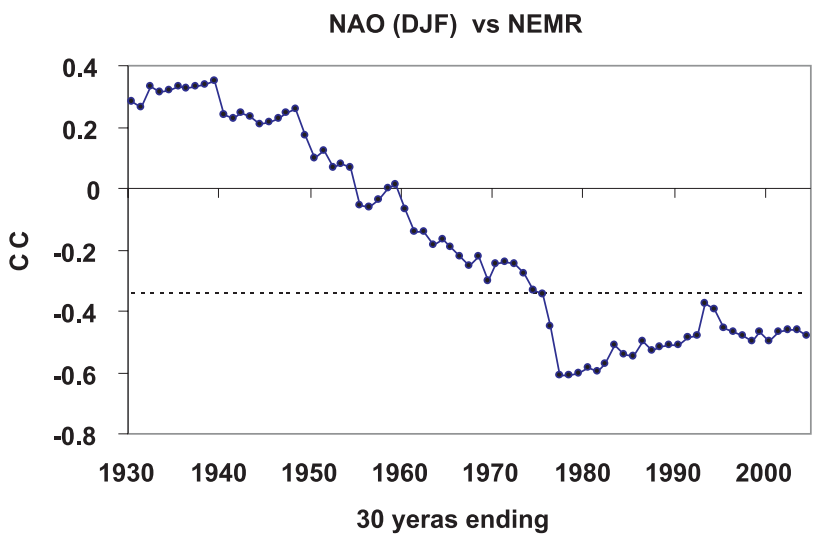

(b)

Figure 8. 30 years moving CCs (a) between NEMR and meridional surface temperature anomaly gradient index (MTAGI) (see text) across Europe and north Africa during September; (b) between NEMR and NAO index during winter. The horizontal dotted line corresponds to CC significant at $5 \%$. correlation between NEMR and January NAO index is shown in figure $8(\mathrm{~b})$. Till the year around 1975, the CC is below $5 \%$ significant level. The highest CC of -0.61 (significant at $1 \%$ ) is observed for the 30 years epoch ending in 1977. During recent times, the value of this CC is -0.48 (significant at $1 \%$ ) for the 30-year epoch ending in 2004. Thus the NAO index during winter season shows significant negative relationship with NEMR. Thus NAO, MTAGI and NEMR seem to be interrelated to each other.

\subsection{Teleconnection between NEMR and sea surface temperature over Pacific Ocean}

As previously shown (figure 3), from the month of April onwards sea surface temperature over the central and eastern equatorial Pacific region shows significant and consistent positive relationship with NEMR while western equatorial Pacific Ocean shows significant inverse relationship with NEMR. On the other hand, the central and eastern equatorial Pacific region sea surface temperature shows significant and consistent negative correlation with ISMR while western equatorial Pacific Ocean shows significant positive correlation with ISMR (e.g., Sikka (1980); Angel (1981)). Thus the equatorial Pacific has dissimilar influence on NEMR and ISMR. Figure 9(a) and (b) depict monthly variation of composite zonal surface air temperature anomaly averaged over western Pacific $\left(110^{\circ} \mathrm{E}-130^{\circ} \mathrm{E}\right)$ and eastern equatorial Pacific $\left(110^{\circ} \mathrm{W}-130^{\circ} \mathrm{W}\right)$ for (excess-deficient) 
(a) $110^{\circ} \mathrm{E}-130^{\circ} \mathrm{E}$

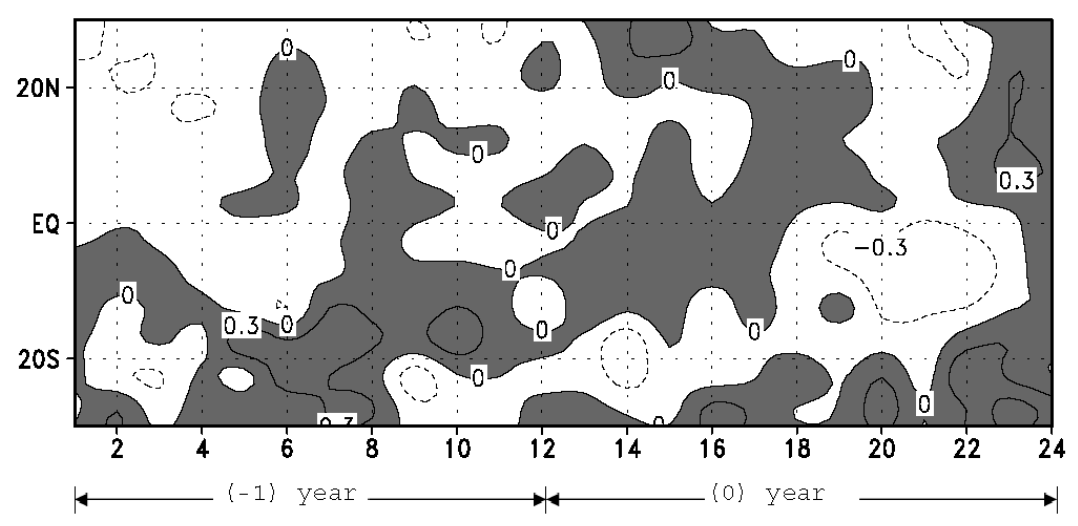

(b) $110^{\circ} \mathrm{W}-130^{\circ} \mathrm{W}$

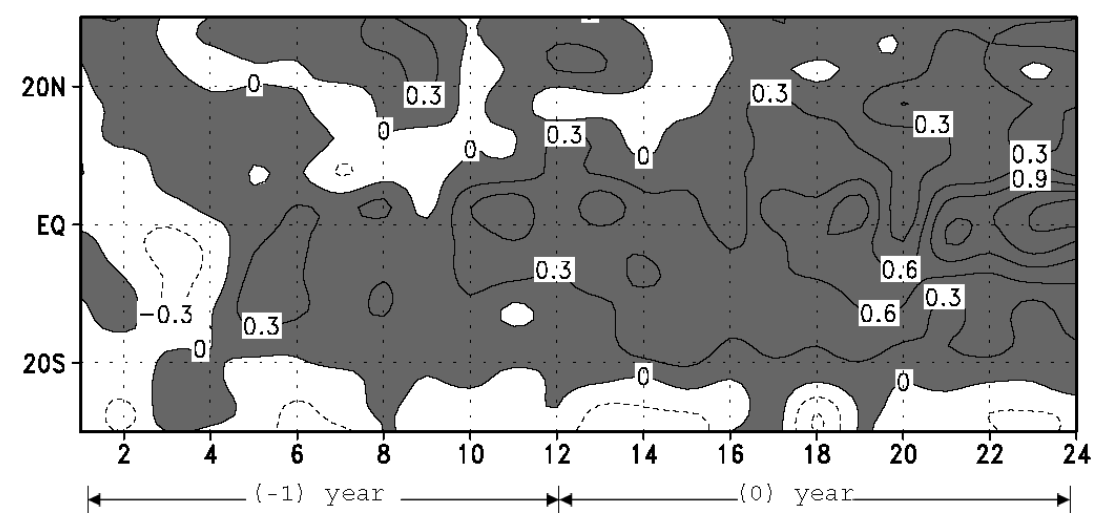

Figure 9. Composites zonal surface temperature anomalies averaged across (a) $110^{\circ} \mathrm{E}-130^{\circ} \mathrm{E}$; (b) $110^{\circ} \mathrm{W}-130^{\circ} \mathrm{W}$ longitudes region for difference between excess and deficient (i.e., excess - deficient) northeast monsoon years. The contour interval is $0.3^{\circ} \mathrm{C}$. The positive values are shaded.

NEMR years. In these figures (0) year and $(-1)$ year denote reference monsoon year and preceding monsoon year respectively. It is seen that the temperatures are warmer than normal from fall season of $(-1)$ year to fall season of $(0)$ year during excess NEMR years over eastern equatorial Pacific. On the other hand, the temperatures are colder than normal from the latter part (August and September) of ISM season to the fall season of (0) year during excess NEMR years over western Pacific region.

There are various studies that discuss the atmospheric teleconnections associated with Pacific Ocean (e.g., Rasmusson and Carpenter (1982)). Recently, G P Singh and J Chattopadhyay (1998) made an analysis of the association between interannual variability of NEMR of Tamil Nadu and southeast India and showed that SST anomalies of antecedent June to August over Nino-4 equatorial Pacific region $\left(5^{\circ} \mathrm{N}-5^{\circ} \mathrm{S} ; 150^{\circ} \mathrm{E}-160^{\circ} \mathrm{W}\right)$ has strong and positive correlation with NEMR. During ElNiño events, the warm sea surface temperature
ZATGI (SEP) vs NEMR

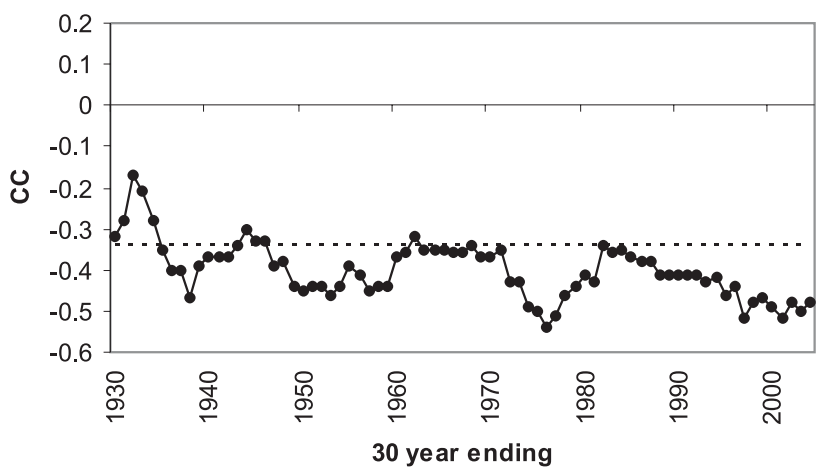

Figure 10. 30 years moving CCs between NEMR and zonal temperature anomaly gradient index (ZTAGI) (see text) across equatorial Pacific during September. The horizontal dotted line corresponds to CC significant at $5 \%$.

over central and eastern equatorial Pacific causes enhanced local exchange of heat and moisture between the ocean and the atmosphere over that region. In the tropics and subtropics of the Pacific 
Ocean, the altered pattern of deep atmospheric convection causes changes in the large scale zonal and meridional circulations of the atmosphere such as the Walker circulation and Hadley cell circulation respectively. The linkage between the El-Niño and climate anomalies occurs through teleconnection involving atmospheric Rossby waves (WMO 1999).

Similar to MTAGI defined earlier, a zonal temperature anomaly gradient index (ZTAGI) is defined as the difference between area averaged surface temperature anomalies over $\left(110^{\circ} \mathrm{E}-130^{\circ} \mathrm{E}\right.$; $\left.15^{\circ} \mathrm{S}-15^{\circ} \mathrm{N}\right)$ and $\left(110^{\circ} \mathrm{W}-130^{\circ} \mathrm{W} ; 10^{\circ} \mathrm{S}-10^{\circ} \mathrm{N}\right)$ during the month of September. The CC between ZTAGI and NEMR is -0.45 (significant at $5 \%$ ). The 30 years sliding CC between September month ZTAGI and NEMR is shown in figure 10. It is seen that CC is significant for most of the 30 years epochs and the value of $\mathrm{CC}$ is -0.51 (significant at $1 \%$ ) during the recent 30 years ending in 2004.

The rainfall series used in the present study refer to the NEMR of Tamil Nadu state. However, coastal Andhra Pradesh (CAP), Kerala, and Rayalaseema are also covered by NEM regime. It has been observed that, based on the 100-year period (1901-2000) rainfall data, there exists a high correlation of the order of 0.87 between NEMR of Tamil Nadu and NEMR of the region covering Tamil Nadu as well as Kerala, CAP and Rayalaseema (Raj et al (2004)). This suggests that the observed features in the present study seem to be valid for the association of NEMR of southern Peninsula with global surface temperature also however this requires further examination.

\section{Conclusions}

Analysis of global surface air temperature anomalies in relation to contrasting NEMR and associated relationship with NAO index was carried out in the present study. Some of the geographical regions that have the potential to give predictive signals for NEMR are listed in table 2. Composite analysis of surface air temperature anomalies indicated that during excess (deficient) NEMR years, the meridional gradient in surface air temperature between Europe and north Africa during the month of September is directed from subtropics (higher) to higher latitudes (subtropics). It is also observed that NAO during September month influences the surface air temperature distribution over north Africa and Europe. A meridional temperature gradient index (MTAGI) between north Africa and Europe showed stable significant inverse relationship with NEMR since 1976. During high (low) phase of NAO, the MTAGI is directed from higher (lower) to lower (higher) latitudes. Also, the NAO index in the month of January showed significant inverse relationship with NEMR since 1976. The central and eastern equatorial Pacific oceanic region has significant and consistent positive correlation with NEMR while the western equatorial region has significant negative correlation with NEMR. A zonal temperature gradient index between eastern equatorial Pacific and western equatorial Pacific showed stable significant inverse relationship with NEMR.

\section{Acknowledgements}

The authors thank the Director General of Meteorology, India Meteorological Department for having provided the facilities to undertake this study and for the permission to publish this work. The authors express thanks to Dr. D S Pai for useful discussions. Also the authors wish to thank the referee for useful comments that helped to improve the original manuscript.

\section{References}

Angell J K 1981 Comparison of variations in atmospheric quantities with SST variations in equatorial eastern Pacific; Mon. Weather Rev. 109 230-243.

Dugam S S, Kakade S B and Verma R K 1997 Interannual and long term variability of Indian monsoon and North Atlantic Oscillation; Theor. Appl. Climatol. 58 21-29.

India Met. Dept. 1973 Northeast monsoon; FMU Rep. No. IV 18.4.

Jones P D, Osborn T J and Brieffa K R 1997 Estimating sampling errors in large-scale temperature averages; J Climatol. 10 2548-2567.

Krishna Rao P R and Jagannathan P 1953 Rainfall of Madras with special reference to Tamil Nadu and Rayalaseema; Memoirs of India Met. Dept. Vol. XXX Part I.

Nicholls N, Gurz G V, Jouzel J, Karl T R, Ogallo L A and Parker D E 1996 Observed climate variability and change, Climate change 1995; In: The science of climate change, (eds) Houghton J T, Meira Filho L G, Callander B A, Harris N, Kattternberg A and Maskell K, Cambridge University Press, pp. 133-192.

Pai D S 2003 Teleconnections of Indian Summer Monsoon with global surface air temperature anomalies; Mausam 54(2) 407-418.

Pai D S 2004 A possible mechanism for the weakening of El Niño - Monsoon relationship during the recent decade; Meteorol. Atmos. Phys. 86 143-157.

Parker D E, Jones P D, Bevan A and Folland C K 1994 Interdecadel changes of surface temperatures since the 19th century; J. Geophys. Res. 99 14,379-14,399.

Raj Y E A, Sen P N and Jamadar S M 1993 Outlook on northeast monsoon rainfall of Tamil Nadu; Mausam 44(1) 19-22.

Raj Y E A 1998 A scheme for advance prediction of northeast monsoon rainfall of Tamil Nadu; Mausam 49(2) $247-254$.

Raj Y E A, Suresh R, Sankaran P V and Amudha B 2004 Seasonal variation of $200 \mathrm{hPa}$ upper tropospheric features 
over India in relation to performance of Indian Southwest and Northeast monsoons; Mausam 55(2) 269-280.

Rajeevan M, Pai D S and Thapliyal V 1998 Spatial and temporal relationships between global and surface air temperature anomalies and Indian summer monsoon; Meteorol. Atmos. Phys. 66 157-171.

Ramaswamy C 1972 The severe drought over Tamil Nadu during the retreating monsoon period of 1968 and its associations with anomalies in the upper level flow patterns over the northern hemisphere; Indian J. Met. Geophys. 23 303-316.

Rasmusson E M and Carpenter T H 1982 Variation in tropical sea surface temperature and surface wind fields associated with southern oscillation/El Niño; Mon. Weather Rev. 110 354-384.

Ropelewski C F and Halpert M S 1987 Global and regional scale precipitation associated with El Niño/southern oscillation; Mon. Weather Rev. 115 1606-1626.

Sikka D R 1980 Some aspects of the large scale fluctuations of summer monsoon rainfall over India in relation to fluctuations in the planetary and regional scale circulation parameters; Proc. Indian Acad. Sci. (Earth Planet. Sci.) 89 179-195.

Singh G P and Chattopadhyaya J 1998 Influence of some circulation anomalies on Indian northeast monsoon; Mausam 49(4) 443-448.

Sridharan S and Muthuswamy A 1990 Northeast monsoon rainfall in relation to El-Niño, QBO and Atlantic hurricane frequency; Vayu Mandal 20(3-4) 104-111.

Van Loon H and Rodgers J C 1978 The seesaw in winter temperatures between Greenland and northern Europe, Part I, General descriptions; Mon. Weather Rev. 106 $296-310$

Verma R K, Subramanian K and Dugam S S 1985 Interannual and long term variability of the summer monsoon and its link with northern hemisphere surface air temperature; Proc. Indian Acad. Sci. (Earth Planet. Sci.) 94 $187-198$

WMO 1966 Climate change; Technical Note No. 79 WMONo. 195:79.

WMO 1999 The 1997-1998 El Niño event; A scientific and technical retrospective, WMO-No. 905. 